Jurnal Personalia, Financial, Operasional,

Markeling dau Sistem Informasi

Performance. Volume 27 Nomor 1 Tahun 2020,60-69

\title{
KEKHAWATIRAN PRIVASI PADA KESUKSESAN ADOPSI FINTECH MENGGUNAKAN MODEL DELONE DAN MCLEAN
}

\author{
Lia Febria Lina ${ }^{{ }^{*}}$, Dhiona Ayu Nani ${ }^{1}$ \\ Fakultas Ekonomi dan Bisnis, Universitas Teknokrat Indonesia \\ *Email corresponding author: liafebrialina@teknokrat.ac.id \\ Diterima 03/01/2020 Direvisi 12/01/2020 Diterbitkan 31/01/2020
}

\begin{abstract}
Abstrak
Industri 4.0 telah menghasilkan banyak perubahan dalam semua bidang industri, salah satunya FinTech sebagai inovasi dalam bidang keuangan. Penelitian ini bertujuan untuk mengisi kesenjangan berbagai penelitian terdahulu dengan menguji Model DeLone dan McLean. Serta menguji bagaimana peran kekhawatiran privasi dapat menurunkan persepsi kualitas informasi pada niat menggunakan FinTech. Objek penelitian ini adalah UMKM di Indonesia. Hasil penelitian ini menunjukkan bahwa persepsi mengenai kualitas informasi dan layanan berpengaruh positif dan signifikan pada niat menggunakan FinTech. Faktor kekhawatiran privasi sebagai variabel moderasi memiliki peran penting dalam mempengaruhi niat mengadopsi teknologi, sehingga seseorang yang memiliki kekhawatiran tinggi dapat menurunkan niat untuk menggunakan pinjaman online. OJK selaku pemilik otoritas tertinggi dalam bidang keuangan dan perbankan, diharapkan dapat menjamin keamanan pinjaman online, agar dapat menurunkan kekhawatiran pemilik UMKM terkait data-data yang mungkin disalahgunakan jika menggunakan pinjaman online.
\end{abstract}

Kata kunci: DeLone dan McLean, FinTech, Kekhawtiran Privasi, Niat Adopsi FinTech.

\begin{abstract}
Industry 4.0 has produced many changes in all industries, one of which is FinTech as an innovation in the financial sector. This study aims to fill the gaps of various previous studies by testing the DeLone and McLean Models. As well as testing how the role of privacy concerns can reduce perceived quality of information on intentions to use FinTech. The object of this research is SMEs in Indonesia. The results of this study indicate that perceptions regarding the quality of information and services have a positive and significant effect on intention to use FinTech. The privacy concern factor as a moderating variable has an important role in influencing the intention to adopt technology, so someone who has high concerns can reduce the intention to use online loans. OJK as the owner of the highest authority in the field of finance and banking, is expected to be able to guarantee the safety of online loans, in order to reduce the concerns of MSME owners regarding data that might be misused if using online loans.
\end{abstract}

Keywords: DeLone and McLean, FinTech, Privacy Concern, FinTech Adoption Intentions. 


\section{PENDAHULUAN}

Revolusi 4.0 yang menggabungkan teknologi dan internet saat ini memberikan peluang yang sangat besar bagi semua aspek. Salah satunya adalah perubahan dalam industri keuangan yang menghasilkan sebuah inovasi yang disebut Financial Technology atau dikenal dengan "FinTech". FinTech adalah kombinasi dari model bisnis yang inovatif dan hasil dari solusi teknologi yang memfasilitasi layanan keuangan yang dapat digunakan sehai-hari (Jin, Seong, \& Khin, 2019) dan dianggap sebagai inovasi penting dalam industri keuangan (Lee \& Shin, 2018). FinTech menjangkau seluruh aspek jasa keuangan, bukan hanya transformasi produk keuangan namun sampai kepada jasa dan pasar keuangan (Chiu, 2017). FinTech telah membawa perkembangan luar biasa dalam ekonomi digital (Peach, 2017; Jin et al., 2019) di berbagai negara seperti di Cina, India dan Inggris. Produk umum untuk FinTech termasuk e-wallet, crypto-currency, pinjaman Peer-to-Peer (P2P), dana kerumunan, dan InsureTech telah menjadi alternatif keuangan utama bagi konsumen dan pelaku bisnis (Jin et al., 2019).

FinTech mulai dimanfaatkan oleh berbagai kalangan, baik individu maupun perusahaan serta menjadi alternatif pendanaan Usaha Mikro Kecil dan Menengah (UMKM). UMKM merupakan salah satu kegiatan bisnis yang mendorong pertumbuhan ekonomi nasional, seperti PDB Nasional dan penyerapan tenaga kerja. Selain itu, UMKM juga menjadi sebuah solusi dalam mengurangi ketimpangan dan kesenjangan pendapatan Indonesia, sehingga pemerintah melalui Kementrian Koperasi dan UMKM sangat mendorong dan mendukung UMKM, bentuk dukungan pemerintah terhadap UMKM termasuk menjembatani dalam peminjaman modal usaha agar dapat berjalan dan berkembang, seperti melakukan penandatanganan kerjasama antara Deputi Bidang Pembiayaan dengan PT. PMN untuk pembiayaan wirausaha pemula, serta dengan PT. Telekomunikasi Indonesia terkait pengembangan usaha pemula di bidang digital (Depkop, 2019), namun belum semua UMKM bisa mendapatkan bantuan ini, tentu saja UMKM harus mencari alternatif pinjaman lain seperti Bank, BPR dan lembaga keuangan lainnya seperti FinTech.

OJK menyatakan bahwa sangat mendorong FinTech sebagai salah satu solusi pendanaan bagi UMKM, namun adopsi FinTech sendiri masih belum mengalami peningkatan (OJK, 2019), sehingga dalam hal ini perlu dipahami faktor-faktor apa yang dapat mempengaruhi UMKM dalam mengadopsi FinTech di Indonesia. Seperti pada kebanyakan negara, di Indonesia FinTech termasuk sektor yang menarik perhatian dan sangat berkembang cepat sejak awal kehadirannya (Davis et al., 2017). Pada tahun 2019 sebanyak 113 FinTech di Indonesia yang terdaftar di OJK dengan jumlah peminjam sebanyak (OJK, 2019). Angka tersebut adalah angka yang cukup tinggi. Meskipun FinTech menarik banyak perhatian, penggunaan FinTech bagi sebagian pengguna masih diragukan.

Beberapa pengguna ragu untuk terus menggunakan FinTech karena memiliki risiko yang cukup besar (Ryu, 2018). Risiko tersebut berkaitan dengan privasi konsumen. Lebih spesifiknya pada tahun 2018 terdapat 130 pelanggan melaporkan bahwa perusahaan FinTech telah menyebarkan data pribadi mereka dan melakukan penagihan bukan hanya kepada peminjam atau kontak darurat yang disertakan ketika perjanjian. Beberapa dari korban merupakan konsumen FinTech yang telah terdaftar di OJK (Tempo, 2018). Hal ini sangat mempengaruhi pengalaman konsumen ketika menggunakan FinTech dan akhirnya kepada keputusan konsumen dalam penggunaan kembali serta berpengaruh pada niat menggunakan FinTech bagi pengguna yang belum menggunakan FinTech. Sehingga, perlu untuk mengkaji terkait persepsi keuntungan seperti kualitas sistem, kualitas informasi, dan kualitas layanan yang dirasakan konsumen. Namun, hal ini juga dipengaruhi oleh faktor konsumen, seperti kekhawatiran privasi. Seseorang yang memiliki tingkat kekhawatiran privasi yang tinggi dapat lebih merasakan resiko 


\section{PERFORMANCE}

Jurnal Personalia, Financial, Operasional,

Marketing dau Sistem Informasi

Performance. Volume 27 Nomor 1 Tahun 2020,60-69

dan akhirnya mengurangi niat menggunakan kembali dan sebaliknya untuk konsumen dengan tingkat kekhawatiran yang rendah dapat terus menggunakan FinTech.

Milian, Spinola, \& Carvalho (2019) melakukan kajian literatur tentang FinTech pada konteks Negara Korea sebanyak 179 publikasi yang terbit mulai dari tahun 1980-2018, pada penelitianya menyatakan bahwa perlu melakukan penelitian dan melakukan pemahaman lebih mendalam terkait FinTech di berbagai negara lain agar mendapat penjelasan yang lebih mendalam. Kajian literatur terkait FinTech juga dilakukan Gomber et al. (2017), sebanyak 142 artikel terkait pembiayaan Digital, Investasi Digital, Uang Digital, Pembayaran Digital, Asuransi Digital, dan Nasihat Keuangan Digital. Hasil kajian literatur menyatakan bahwa penelitian terkait hal tersebut adalah penelitian masa depan yang perlu dikaji lebih lanjut serta penelitian terkait dengan prilaku konsumen dalam penerimaan FinTech pada berbagai penelitian menggunakan The Unified Theory of Acceptance and Use of Technology Model (2003), The Technology Acceptance Model (1989) dan Innovation Adoption Models. Sehingga penelitian ini bertujuan untuk mengisi kesesenjangan berbagai penelitian (Lu, Yang, Chau, \& Cao, 2011; Milian et al., 2019; Gomber et al, 2017) dan melakukan penelitian di Negara Asia khususnya di Indonesia dan menggunakan teori tentang penerimaan teknologi menggunakan DeLone dan McLean Teori yang belum banyak diteliti. Davis et al. (2017) melakukan penelitian tentang perkembangan dan pemahaman berbagai resiko yang dihasilkan inovasi FinTech di Indonesia, penelitiannya menyatakan bahwa risiko dan peluang terkait FinTech di Indonesia lebih besar jika dibandingkan dengan negara maju. Selain itu, adopsi teknologi adalah langkah awal yang sangat penting untuk keberlangsungan bisnis di era teknologi (Bhattacherjee, 2001). Sehingga sangat penting untuk mengkaji lebih dalam bagaimana FinTech dapat diterima oleh konsumen dan hal-hal yang mempengaruhi, karena hal ini penting baik bagi pemasar atau bagi konsumen.

\section{TINJAUAN PUSTAKA DAN PERUMUSAN HIPOTESIS}

\section{Model DeLone dan McLean (D\&M) terbaru (2003) (The Updated D\&M IS Success Model)}

Model ini meninjau ukuran keberhasilan sistem informasi melalui enam komponen yaitu kualitas sistem, kualitas informasi, kualitas layanan, niat menggunakan, kepuasan pengguna, dan manfaat. Beberapa studi telah menggunakan Model D\&M (Wang \& Liao, 2008); Fang, Chiu, \& Wang, 2011; Ramírez-Correa, Rondán-Cataluña, \& Arenas-Gaitán, 2018; Aldholay, Isaac, Abdullah, Abdulsalam, \& Al-Shibami, 2018; dan Aldholay, Abdullah, Isaac, \& Mutahar, 2019). Wang \& Liao (2008) menggunakan model ini untuk menilai keberhasilan sistem e-government pada perspektif masyarakat di Taiwan. Fang, Chiu, \& Wang (2010) menggunakan Model D\&M untuk menguji kepuasan pelanggan dan niat pembelian ulang. Ramírez-Correa, Rondán-Cataluña, \& Arenas-Gaitán (2018) menggunakan Model D\&M untuk mengeksplorasi kepuasan siswa terhadap sistem informasi di pendidikan tinggi. Studi yang dilakukan Aldholay et al. (2018) menggunakan Model D\&M untuk mengukur kualitas sistem pembelajaran online di Yaman. Selanjutnya, Aldholay et al. (2019) menggunakan Model D\&M kembali untuk memperluas studinya mengenai perspektif siswa di Yaman terhadap penggunaan sistem pembelajaran online. Studi ini menggunakan tiga komponen dalam Model D\&M (2003) yaitu kualitas sistem, kualitas informasi, dan kualitas layanan untuk menguji pengaruhnya pada niat menggunakan FinTech. Ketiga komponen ini digunakan karena kaitannya dengan penggunaan teknologi yang dalam hal ini yaitu FinTech. Kualitas sistem mencangkup kegunaan, ketersediaan, keandalan, kemampuan beradaptasi, dan waktu respon dari FinTech. Kualitas informasi mencangkup konten dari FinTech yang lengkap, relevan, mudah dipahami, dan aman jika mengharapkan pengguna ketika menggunakan FinTech. 
FinTech

Performance. Volume 27 Nomor 1 Tahun 2020,60-69

Menurut Bank Indonesia (bi.go.id) FinTech merupakan hasil gabungan antara jasa keuangan dengan teknologi. Bisnis model dari FinTech adalah hasil dari perubahan konvensional menjadi moderat, yang awalnya dalam membayar harus bertatap-muka dan harus membawa sejumlah uang kas, kini konsumen dapat melakukan transaksi jarak jauh dengan melakukan pembayaran yang dapat dilakukan dalam hitungan detik saja. Menurut Stewart dan Jurjens (2018) FinTech dikategorikan sebagai pemanfaatan perangkat seluler dan berbagai platform teknologi lainnya untuk mengakses rekening bank, notifikasi transaksi, dan peringatan debit dan kredit dengan cara push notification melalui APP, SMS atau bentuk pemberitahuan lainnya. FinTech memiliki berbagai jenis yaitu e-wallet, crypto-currency, Pinjaman Peer-to-Peer (P2P), dana kerumunan, dan InsureTech yang telah menjadi alternatif keuangan utama bagi konsumen dan bisnis (Jin et al., 2019). Penelitian ini berfokus pada Peer to Peer lending (P2P), menurut Davis et al. (2017) P2P didefinisikan sebagai pialang yang mencocokkan investor dengan peminjam, dan memutuskan kemungkinan diterimanya pengajuan pinjaman di FinTech. Jika dibandingkan dengan aktivitas broker tradisional, FinTech memberikan kemudahan seperti memungkinkan kontrak elektronik, pembagian kontrak pinjaman di banyak pemberi pinjaman atau investor, diversifikasi investor, penggunaan lebih banyak informasi dalam penilaian kredit dan penetapan harga pinjaman berbasis risiko, dan metode algoritmik untuk mencocokkan banyak peminjam dan pemberi pinjaman dan menentukan suku bunga yang terlibat. Namun, hal tersebut juga menimbulkan resiko yang dihadapi konsumen seperti tidak mendapatkan pinjaman yang sesuai seperti suku bunga berlebihan, menghadapi penagihan utang yang tidak pantas jika pembayaran tidak terpenuhi, dan menghadapi risiko privasi seperti penyalah gunaan informasi pribadi.

\section{Kekhawatiran Privasi}

Konsep privasi sudah ada sejak lama dari berbagai disiplin ilmu seperti psikologi, antropologi sampai pada manajemen (Tan, Qin, Kim, \& Hsu, 2012). Menurut Tan et al. (2012) kekhawatiran privasi adalah kesadaran dan penilaian risiko seseorang terkait dengan pelanggaran privasi. Penelitian Kim \& Huh (2017) dalam konteks iklan juga mendefinisikan kekhawatiran privasi sebagai sejauh mana konsumen khawatir tentang potensi penyalahgunaan dari data daringnya yang dikumpulkan oleh pihak lain. Sehingga penelitian ini mendefinisikan kekhawatiran privasi sebagai kesadaran atau perasaan yang dimiliki konsumen tentang potensi penyalahgunaan informasi pribadi yang mungkin dapat digunakan pihak FinTech. Isue privasi adalah faktor penentu dalam mengadopsi inovasi dalam teknologi (Kim \& Huh, 2017).

\section{Perumusan Hipotesis}

\section{Pengaruh Kualitas Informasi pada Niat menggunakan FinTech}

Kualitas informasi mencangkup konten dari FinTech yang lengkap, relevan, mudah dipahami, dan aman yang diharapkan pengguna ketika menggunakan FinTech (DeLone dan McLean, 2004). Ketika pengguna merasa informasi yang ditawarkan oleh sebuah aplikasi memberikan manfaat dan bernilai dapat mendorong pengguna untuk selalu mengakses aplikasi dan kepuasan pada aplikasi (Han, Park, Chung, \& Lee, 2016; Sharma dan Sharma, 2019). Sehingga dibentuk hipotesis sebagai berikut:

H1: Kualitas Informasi Berpengaruh Positif pada Niat menggunakan FinTech

\section{Pengaruh Kualitas Sistem pada Niat Menggunakan FinTech}

Menurut DeLone dan McLean (2004) kualitas sistem dalam lingkup internet mencangkup kegunaan, ketersediaan, keandalan, kemampuan beradaptasi, dan waktu respon dari aplikasi FinTech. Kualitas sistem juga merupakan salah satu motivasi pengguna ketika ingin menggunakan sebuah teknologi baru (Chemingui \& Ben, 2013). FinTech termasuk kedalam teknologi baru yang 


\section{PERFORMANCE}

Jurnal Personalia, Financial, Operasional,

Marketing dau Sistem Informasi

Performance. Volume 27 Nomor 1 Tahun 2020,60-69

harus memperhatikan kualitas dari sistemnya, sehingga ketika pengguna merasa dimudahkan dalam mengakses aplikasi dapat mendorong niat menggunakan aplikasi. Upadhyay \& Jahanyan (2016) melakukan penelitian tentang faktor-faktor yang mempengaruhi adopsi aplikasi pembayaran menggunakan berbagai model dan teori adopsi teknologi. Salah satu variabel yang digunakan adalah kualitas sistem yang diuji pengaruhnya pada kemudahan dan niat menggunakan teknologi. Penelitian Baabdullah, Alalwan, Rana, Kizgin, \& Patil, (2019) juga melakukan penelitian di Negara Saudia Arabia dengan menggabungkan model UTAUT2 dan the D\&M IS Success Model, dalam penelitian tersebut kualitas sistem berpengaruh signifikan pada penggunaan aplikasi mobile banking. Kualitas sistem juga berpengaruh pada kepercayaan yang mengarah pada niat untuk menggunakan FinTech (Chemingui \& Ben, 2013). Ketika kualitas sistem buruk, susah di akses maka mendorong rendahnya persepsi pengguna pada niat untuk menggunakan aplikasi. Kualitas sistem yang baik membuat pengguna merasa mudah dalam menggunakan aplikasi dapat meningkatkan niat untuk menggunakan aplikasi FinTech. Sehingga dibentuk hipotesis:

H2: Kualitas Sistem Berpengaruh Positif pada Niat Menggunakan FinTech

\section{Pengaruh Kualitas Layanan pada Niat Menggunakan FinTech}

Kualitas layanan mencangkup dukungan yang diberikan penyedia layanan seperti perhatian khusus dan jaminan keamanan terhadap pengguna. (DeLone dan McLean, 2004). Kualitas layanan disebut sebagai kunci dari pendorong niat menggunakan dan kepuasan dalam menggunakan mobile banking (Sharma dan Sharma, 2019). Berbagai penelitian telah menguji kualitas layanan sebagai salah satu pendorong efektifitas dan keberhasilan sebuah system informasi teknologi. Pengguna mendapatkan kemudahan dalam layanan personal seperti mengerti dan memahami permasalahan yang dialami pengguna maka dapat meningkatkan pengalaman dan interaksi dalam aplikasi tersebut yang akhirnya dapat mendorong niat untuk menggunakan aplikasi (Sharma dan Sharma, 2019; Baabdullah et al., 2019; Wilson dan Mbamba, 2017). Sehingga dibentuk hipotesis sebagai berikut:

H3: Kualitas Layanan Berpengaruh Positif pada Niat Menggunakan Kembali FinTech

\section{Moderasi Kekhawatiran Privasi pada Niat Menggunakan FinTech}

Kekhawatiran privasi mengacu pada perasaan negatif terkait dengan resiko yang dirasakan seseorang. Menurut Teori emosi kognitif, tekanan emosi dapat berpengaruh pada resiko dan kepercayaan. Emosi positif dapat membentuk persepsi positif dalam kualitas dari suatu produk atau jasa dalam perusahaan (Lim, Sung, Kim, \& Kim, 2017). Sehingga, emosi negatif dapat memungkinkan menurunkan persepsi kualitas pada suatu teknologi atau produk. Hal ini di buktikan dalam penelitian kekhawatiran privasi diuji sebagai variabel moderasi, seseorang yang memiliki kekhawatiran tinggi dapat menurunkan niat untuk penerimaan inovasi teknologi sampai kepada niat beli pada suatu produk (Van Doorn \& Hoekstra, 2013; Tan et al, 2012). Privasi juga dianggap sebagai resiko yang sangat dihindari, pengguna yang memiliki persepsi resiko yang tinggi dapat menurunkan niat beli pada suatu produk (de Kerviler, Demoulin, \& Zidda, 2016). Persepsi pengguna yang positif dari kualitas informasi dapat menurun ketika memiliki kekhawatiran privasi yang tinggi. Dari penjelasan diatas, maka dibentuk hipotesis empat sebagai berikut:

H4: Kekhawatiran Privasi Memperlemah Hubungan Kualitas Informasi pada Niat Menggunakan FinTech 


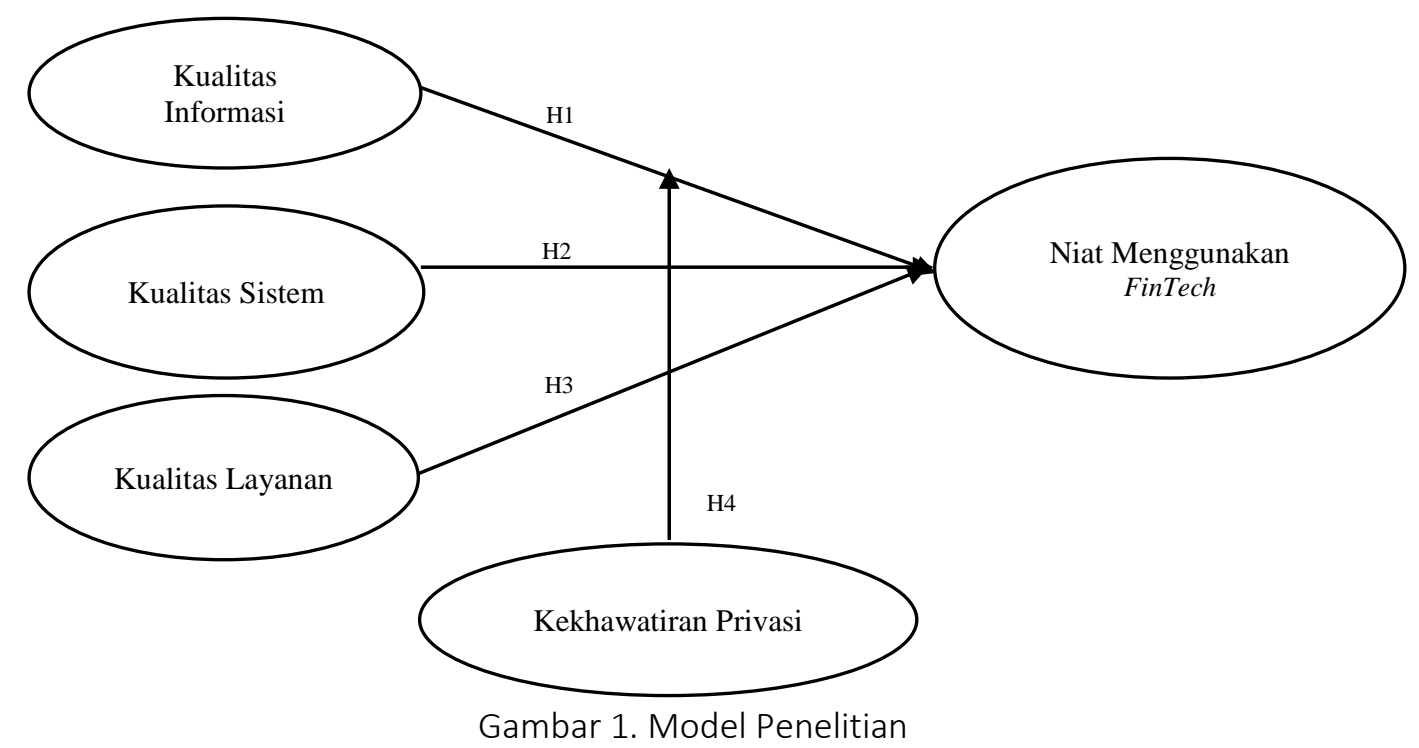

\section{METODE PENELITIAN}

Penelitian ini menggunakan pendekatan kuantitatif. Jenis data yang digunakan adalah data primer. Data dikumpulkan melalui kuesioner yang didistribusikan secara langsung maupun online. Waktu pengumpulan data dalam penelitian ini dilakukan selama kurang lebih satu bulan. Selama satu bulan, kuesioner didistribusikan kepada pemilik UMKM di Indonesia. Penelitian ini menggunakan teknik non probability sampling jenis purposive sampling dengan memilih sampel dengan kriteria tertentu. Sampel yang digunakan dalam penelitian ini adalah 102 pemilik UMKM dengan kriteria UMKM yang telah berdiri kurang dari dua tahun. Pemilihan kriteria ini dikarenakan UMKM yang berdiri dalam waktu kurang dari dua tahun masih dalam proses perkembangan dan membutuhkan modal usaha.

Total kuesioner yang didistribusikan sebanyak 300. Sebanyak 200 kuesioner didistribusikan secara online dan 100 kuesioner secara langsung. Sebelum pengisian kuesioner dilakukan, peneliti memastikan bahwa semua responden dalam penelitian memiliki pengetahuan tentang pinjaman online. Total responden yang memiliki pengetahuan mengenai pinjaman online adalah sebanyak 150 responden. 102 responden termasuk ke dalam kriteria sampel, sementara sisanya tidak dapat digunakan karena tidak memenuhi kriteria sampel penelitian karena tidak mengetahui tentang pinjaman online. Instrumen penelitian diadaptasi dari beberapa penelitian terdahulu. Kualitas informasi, kualitas sistem, dan kualitas layanan diadaptasi dari DeLone \& McLean (2003), kekhawatiran privasi diadaptasi dari Featherman \& Pavlou (2003), niat menggunakan pinjaman online diadaptasi dari Cheng, Lam, \& Yeung (2006).

Instrumen penelitian diuji dengan uji validitas dan reliabilitas. Uji validitas dilakukan dengan melihat nilai Average Variance Extracted (AVE), jika nilai AVE > 0,5 maka instrumen dinyatakan valid (Hair et al., 2010). Uji reliabilitas dilakukan dengan melihat nilai Cronbach's alpha, jika nilai alpha > 0,7 instrumen dinyatakan reliabel (Hair et al., 2010). Setelah pengujian instrumen, kemudian dilakukan pengujian hipotesis menggunakan teknik analisis SEM-PLS dengan alat analisis WrapPLS 6.0.

\section{HASIL DAN PEMBAHASAN}

Hasil pengujian instrumen penelitian menunjukkan nilai AVE untuk setiap konstruk $>0,5$ dan Cronbach's alpha $>0,7$. Hasil ini menunjukkan bahwa instrumen penelitian valid dan reliabel. 
Performance. Volume 27 Nomor 1 Tahun 2020,60-69

Tabel 1. Validitas dan Reliabilitas

\begin{tabular}{|l|l|l|l|l|l|}
\hline & KI & KS & KL & INT & KP \\
\hline AVE & 0,697 & 0,594 & 0,809 & 0,888 & 0,817 \\
\hline Cronbach's Alpha & 0,891 & 0,826 & 0,882 & 0,936 & 0,887 \\
\hline
\end{tabular}

Sumber: Data Diolah (2019).

Setelah instrumen penelitian dinyatakan valid dan reliabel, selanjutnya dilakukan pengujian hipotesis. Hasil pengujian hipotesis menunjukkan bahwa kualitas informasi berpengaruh positif dan signifikan terhadap niat menggunakan FinTech, hal ini menunjukkan Hipotesis 1 terdukung $(P=<0,01$ dan $\beta=0,29)$. Pengujian hipotesis juga menunjukkan dukungan untuk Hipotesis $3 \mathrm{di}$ mana kualitas layanan berpengaruh positif dan signifikan terhadap niat menggunakan FinTech $(P=<0,01$ dan $\beta=0,50)$. Sementara itu, tidak ditemukan dukungan untuk Hipotesis 2 di mana kualitas sistem tidak berpengaruh pada niat menggunakan FinTech $(P=0,32$ dan $\beta=0,05)$. Selanjutnya, kekhawatiran privasi memperlemah hubungan antara kualitas informasi dan niat menggunakan FinTech, sehingga Hipotesis 4 terdukung $(P=0.04$ dan $\beta=0,18)$.

Hasil pengujian Hipotesis 1 sejalan dengan hasil dari berbagai penelitian yang menyatakan bahwa pengguna yang memiliki persepsi bahwa aplikasi memberikan informasi yang berkualitas dapat meningkatkan niat untuk mengadopsi (Wilson \& Mbamba, 2017), hal ini juga didukung oleh penelitian Han et al. (2016) serta penelitian Sharma \& Sharma (2019), yang menyatakan bahwa aplikasi yang dapat memberikan informasi yang bermanfaat dan bernilai dapat mendorong pengguna selalu mengakses aplikasi dan juga memberikan kepuasan dalam menggunakan aplikasi.

Hasil pengujian Hipotesis 2 tidak sejalan dengan yang diharapkan karena kualitas sistem tidak memiliki pengaruh pada niat menggunakan FinTech. Hasil penelitian ini sejalan dengan penelitian (Sharma \& Sharma, 2019), hal ini mengindikasikan bahwa kualitas sistem bukan faktor utama yang mendorong pengguna untuk mengadopsi sebuah inovasi teknologi. Hal ini juga berlaku bagi pemilik UMKM dalam mengadopsi FinTech.

Kualitas layanan berpengaruh positif pada niat menggunakan FinTech. Hasil pengujian Hipotesis 3 sejalan dengan beberapa penelitian (Sharma\& Sharma, 2019; Baabdullah et al., 2019; Wilson \& Mbamba, 2017). Pengguna yang memiliki persepsi bahwa FinTech dapat memberikan kemudahan dalam pelayanan personal seperti mengerti dan memahami permasalahan yang dialami pengguna maka dapat meningkatkan pengalaman dan interaksi, sehingga dapat mendorong niat untuk menggunakan FinTech.

Hasil pengujian Hipotesis 4, yaitu kekhawatiran privasi memperlemah hubungan kualitas informasi pada niat menggunakan FinTech telah membuktikan bahwa faktor konsumen sangat memberikan peran penting dalam hasil penelitian ini. Pengguna yang memiliki tingkat kekhawatiran tinggi dapat menurunkan niat untuk menggunakan FinTech, hal ini juga sejalan dengan penelitian yang dilakukan oleh van Doorn \& Hoekstra (2013) dan Tan, Qin, Kim, \& Hsu, 2012) dalam konteks periklanan, bahwa pengguna yang memiliki kekhawatiran yang tinggi dapat menurunkan niat membeli produk yang ditampilkan lewat iklan yang disesuaikan dengan data pribadi, sehingga faktor konsumen sangat berperan penting dalam mempengaruhi niat adopsi di berbagai inovasi teknologi.

\section{KESIMPULAN}

Berdasarkan temuan penelitian, dapat disimpulkan bahwa semakin tinggi kualitas informasi dan layanan pada FinTech maka semakin tinggi niat UMKM dalam menggunakan pinjaman online. Informasi dikatakan berkualitas dilihat dari kebaharuan, kelengkapan, dan kredibilitas suatu informasi. Selanjutnya, layanan yang berkualitas dapat dipersepsikan dari kemudahan, 


\section{PERFORMANCE}

Jurnal Personalia, Financial, Operasional,

Marketing dau Sistem Informasi

Performance. Volume 27 Nomor 1 Tahun 2020,60-69

keamanan, dan perhatian bagi pengguna. Pemilik UMKM dapat mempertimbangkan hal tersebut dalam menentukan keputusan untuk mengadopsi sistem pinjaman online bagi usahanya. Temuan penelitian ini juga menunjukkan bahwa faktor kekhawatiran privasi pengguna memiliki peran penting dalam mempengaruhi niat mengadopsi teknologi, sehingga dalam penelitian ini membuktikan bahwa seseorang yang memiliki kekhawatiran tinggi dapat menurunkan niat untuk menggunakan pinjaman online.

Sampai saat ini, FinTech sebagai inovasi teknologi keuangan khususnya pinjaman online yang diyakini sebagai alternatif pinjaman selain perbankan masih belum dikenal oleh masyarakat khususnya pemilik UMKM di Indonesia yang dilihat dari tingkat respon yang mengetahui tentang pinjaman online hanya 34\%, sementara sisanya tidak mengetahui. Hal ini dikarenakan kurangnya sosialisasi mengenai pinjaman online dikalangan UMKM. Selain itu, tingginya kekhawatiran privasi pemilik UMKM dapat mempengaruhi niat menggunakan pinjaman online. Dalam hal ini OJK selaku pemilik otoritas tertinggi dalam bidang keuangan dan perbankan, diharapkan dapat menjamin keamanan pinjaman online, sehingga menurunkan kekhawatiran pemilik UMKM terkait data-data yang mungkin disalahgunakan jika menggunakan pinjaman online.

Penelitian ini tidak terlepas dari keterbatasan. Pertama, penelitian ini menguji model Delone \& McLean pada niat menggunakan pinjaman online bagi pemilik UMKM yang hasilnya masih menunjukkan inkonsistensi dengan penelitian sebelumnya, sehingga penelitian selanjutnya dapat mengadaptasi kembali model penelitian ini. Kedua, jumlah sampel pada penelitian ini masih terbatas yaitu 102 responden. Hasil ini belum dapat mewakili populasi UMKM di Indonesia, sehingga penelitian selanjutnya dapat memperluas sampel penelitian. Terakhir, penelitian ini hanya menggunakan salah satu faktor konsumen yaitu kekhawatiran privasi. Penelitian selanjutnya dapat menambahkan faktor lain dalam personality trait seperti keterbukaan dan antusiasme.

\section{DAFTAR PUSTAKA}

Aldholay, A., Abdullah, Z., Isaac, O., \& Mutahar, A. M. (2019). Perspective of Yemeni students on use of online learning: Extending the information systems success model with transformational leadership and compatibility. Information Technology and People. https://doi.org/10.1108/ITP-02-2018-0095

Aldholay, A., Isaac, O., Abdullah, Z., Abdulsalam, R., \& Al-Shibami, A. H. (2018). An extension of Delone and McLean IS success model with self-efficacy: Online learning usage in Yemen. International Journal of Information and Learning Technology, 35(4), 285-304. https://doi.org/10.1108/IJILT-11-2017-0116

Baabdullah, A. M., Alalwan, A. A., Rana, N. P., Kizgin, H., \& Patil, P. (2019). Consumer use of mobile banking (M-Banking) in Saudi Arabia: Towards an integrated model. International Journal of Information Management, 44(September 2018),38-52. https://doi.org/10.1016/j.ijinfomgt.2018.09.002

Chemingui, H., \& Ben, H. (2013). Resistance, motivations, trust and intention to use mobile financial services. https://doi.org/10.1108/IJBM-12-2012-0124

Cheng, T. C. E., Lam, D. Y. C., \& Yeung, A. C. L. (2006). Adoption of internet banking: An empirical study in Hong Kong. Decision Support Systems, 42(3), 1558-1572. https://doi.org/10.1016/j.dss.2006.01.002

Chiu, I. H. Y. (2017). A new era in fintech payment innovations? A perspective from the institutions 
Jurnal Personalia, Financial, Operasional,

Marketing dau Sistem Informasi

Performance. Volume 27 Nomor 1 Tahun 2020,60-69

and regulation of payment systems. Law, Innovation and Technology (Vol. 9). Taylor \& Francis. https://doi.org/10.1080/17579961.2017.1377912

de Kerviler, G., Demoulin, N. T. M., \& Zidda, P. (2016). Adoption of in-store mobile payment: Are perceived risk and convenience the only drivers? Journal of Retailing and Consumer Services, 31, 334-344. https://doi.org/10.1016/j.jretconser.2016.04.011

DeLone, W. H., \& McLean, E. R. (2003). The DeLone and McLean model of information systems success: A ten-year update. Journal of Management Information Systems, 19(4), 9-30. https://doi.org/10.1080/07421222.2003.11045748

Fang, Y. H., Chiu, C. M., \& Wang, E. T. G. (2011). Understanding customers' satisfaction and repurchase intentions: An integration of IS success model, trust, and justice. Internet Research, 21(4), 479-503. https://doi.org/10.1108/10662241111158335

Featherman, M. S., \& Pavlou, P. A. (2003). Predicting e-services adoption: A perceived risk facets perspective. International Journal of Human Computer Studies, 59(4), 451-474. https://doi.org/10.1016/S1071-5819(03)00111-3

Hair, J., Black, W., Babin, B., \& Anderson, R. (2010). Multivariate Data Analysis: A Global Perspective. In Multivariate Data Analysis: A Global Perspective.

Han, H., Park, A., Chung, N., \& Lee, K. J. (2016). A near field communication adoption and its impact on Expo visitors' behavior. International Journal of Information Management, 36(6), 1328-1339. https://doi.org/10.1016/j.ijinfomgt.2016.04.003

Jin, C. C., Seong, L. C., \& Khin, A. A. (2019). Factors Affecting the Consumer Acceptance towards Fintech Products and Services in Malaysia. International Journal of Asian Social Science, 9(1), 59-65. https://doi.org/10.18488/journal.1.2019.91.59.65

Kajian Perlindungan Konsumen Sektor Jasa Keuangan Pada FinTech Tahun 2017.

Kemenkop dan UMKM Terus Dorong Kemajuan UMKM di Indonesia. (2019). Diakses pada 18 Agustus 2019, dari Kementerian Koperasi dan UMKM: http://depkop.go.id.

Kim, H., \& Huh, J. (2017). Perceived Relevance and Privacy Concern Regarding Online Behavioral Advertising (OBA) and Their Role in Consumer Responses. Journal of Current Issues and Research in Advertising, 38(1), 92-105. https://doi.org/10.1080/10641734.2016.1233157

Lee, I., \& Shin, Y. J. (2018). Fintech: Ecosystem, business models, investment decisions, and challenges. Business Horizons, 61(1), 35-46. https://doi.org/10.1016/j.bushor.2017.09.003

Lim, S. H., Sung, J., Kim, D., \& Kim, D. J. (2017). A Study of Consumers' Perceived Risk, Privacy Concern, Information Protection Policy, and Service Satisfaction in the Context of Parcel Delivery Services. Asia Pacific Journal of Information Systems, 27(3), 156-175. https://doi.org/10.14329/apjis.2017.27.3.156

Lu, Y., Yang, S., Chau, P. Y. K., \& Cao, Y. (2011). Dynamics between the trust transfer process and intention to use mobile payment services: A cross-environment perspective. Information and Management, 48(8), 393-403. https://doi.org/10.1016/j.im.2011.09.006 
Jurnal Personalia, Financial, Operasional,

Marketing dam Sistem Informasi

Performance. Volume 27 Nomor 1 Tahun 2020,60-69

Milian, E. Z., Spinola, M. de M., \& Carvalho, M. M. d. (2019). Fintechs: A literature review and research agenda. Electronic Commerce Research and Applications, 34, 100833. https://doi.org/10.1016/j.elerap.2019.100833

Ramírez-Correa, P. E., Rondán-Cataluña, F. J., \& Arenas-Gaitán, J. (2018). Student information system satisfaction in higher education: the role of visual aesthetics. Kybernetes, 47(8), 1604-1622. https://doi.org/10.1108/K-08-2017-0297

Sharma, S. K., \& Sharma, M. (2019). Examining the role of trust and quality dimensions in the actual usage of mobile banking services: An empirical investigation. International Journal of Information Management, 44(September 2018),65-75. https://doi.org/10.1016/j.ijinfomgt.2018.09.013

Siaran Pers Arahkan FinTech Lending Kembangkan UMKM. (2017). Diakses 18 Agustus 2019, dari Otoritas Jasa Keuangan: https://www.ojk.go.id/id/Default.aspx.

Tan, X., Qin, L., Kim, Y., \& Hsu, J. (2012). Impact of privacy concern in social networking web sites. Internet Research, 22(2),211-233. https://doi.org/10.1108/10662241211214575

van Doorn, J., \& Hoekstra, J. C. (2013). Customization of online advertising: The role of intrusiveness. Marketing Letters, 24(4),339-351. https://doi.org/10.1007/s11002-0129222-1

Wang, Y. S., \& Liao, Y. W. (2008). Assessing eGovernment systems success: A validation of the DeLone and McLean model of information systems success. Government Information Quarterly, 25(4), 717-733. https://doi.org/10.1016/j.giq.2007.06.002

Wilson, V., \& Mbamba, UI. (2017). Acceptance of Mobile Phone Payments Systems in Tanzania: Technology Acceptance Model Approach. AT Business Management Review, 20(2), 15-25. 